\title{
Diagnóstico do complexo teníase-cisticercose bovina em São João Evangelista, Minas Gerais, Brasil
}

\author{
[Diagnosis of Bovine Taeniasis-Cysticercosis Complex in São João Evangelista, \\ Minas Gerais, Brazil] \\ F.L. Garro ${ }^{1}$, T.M. Santos ${ }^{2}$, D.C.S. Assis ${ }^{1 *}$, L.G.D. Heneine ${ }^{3}$, C.B.D. Ornellas ${ }^{1}$, \\ P.S.A. Pinto ${ }^{4}$, W.L.M. Santos ${ }^{1}$ \\ ${ }^{1}$ Escola de Veterinária-Universidade Federal de Minas Gerais - UFMG - Belo Horizonte, MG \\ ${ }^{2}$ Instituto Federal do Norte de Minas Gerais - IFNMG - Montes Claros, MG \\ ${ }^{3}$ Fundação Ezequiel Dias - FUNED - Belo Horizonte, MG \\ ${ }^{4}$ Universidade Federal de Viçosa - UFV - Viçosa, MG
}

\section{RESUMO}

Com o objetivo de diagnosticar a situação do complexo teníase-cisticercose bovina em Minas Gerais, Brasil, foi selecionado o município de São João Evangelista, onde foram coletadas amostras de sangue de 339 bovinos em 15 propriedades rurais, sorteadas aleatoriamente. Em cada propriedade, foi aplicado um questionário socioeconômico para a análise de fatores que favorecem a manutenção do complexo teníasecisticercose bovina. Foi realizado também o diagnóstico de teníase humana por meio de exame coproparasitológico dos habitantes das propriedades. Encontrou-se a prevalência de 4,1\% para cisticercose bovina e a frequência de $2,94 \%$ para teníase humana. Entre os fatores de risco para a manutenção do complexo teníase-cisticercose analisados, foi observada uma relação estatisticamente significativa $(\mathrm{P}=0,042)$ entre a ocorrência de cisticercose bovina e a ingestão de carne malpassada pelos entrevistados. Concluiu-se que a cisticercose bovina está presente no município de São João Evangelista, MG, em índices considerados endêmicos, sendo o consumo de carne malpassada e não inspecionada o principal fator de risco para a manutenção do complexo teníase-cisticercose, o que reforça a necessidade da adoção de medidas de controle com contínua vigilância epidemiológica e sanitária.

Palavras-chave: bovino, cisticercose, ELISA, Immunoblot, teníase

\begin{abstract}
In order to diagnose the situation of bovine taeniasis-cysticercosis complex in the state of Minas Gerais, Brazil, the city of São João Evangelista was selected, and blood samples were collected from 339 cattle in 15 randomly selected farms. A socioeconomic questionnaire was filled in each property for the analysis of the factors that favor the maintenance of the taeniasis-cysticercosis complex. Additionally, there was the diagnosis of human taeniasis verified by stool examinations of the properties' inhabitants. A prevalence of $4.1 \%$ for bovine cysticercosis and the frequency of $2.94 \%$ for human taeniasis were found. Among the risk factors, a statistically significant relation $(p=0.042)$ was found between the occurrence of bovine cysticercosis and the ingestion of undercooked meat. It was concluded that bovine cysticercosis is broadly distributed in the city of São João Evangelista, with rates considered endemic, being the consumption of raw and not-inspected meat the main riskfactors for the maintenance of complex taeniasis-cysticercosis, reinforcing the need to adopt control measures with continuous epidemiological and health surveillance.
\end{abstract}

Keywords: bovine, cysticercosis, ELISA, immunoblot, taeniasis

Recebido em 20 de fevereiro de 2015

Aceito em 15 de junho de 2015

*Autor para correspondência (corresponding autor)

E-mail: deborasampaio11@gmail.com 


\section{INTRODUÇÃO}

O complexo teníase-cisticercose engloba duas enfermidades distintas, causadas pelo mesmo cestódeo em diferentes estágios de desenvolvimento. A cisticercose em bovinos é caracterizada pela presença da forma larvar de Taenia saginata, denominada Cysticercus bovis, nos tecidos desses animais, enquanto a teníase é provocada pela presença da forma adulta do parasita no intestino delgado dos seres humanos, que são hospedeiros definitivos (Pfuetzenreiter e Ávila-Pires, 2000). Estima-se que as perdas causadas anualmente sejam de US\$ 3 a 4 bilhões, considerando os gastos com medidas de controle e prevenção, a condenação ou o aproveitamento condicional das carcaças bovinas, bem como os custos de tratamento de humanos infectados (Ungar et al., 2008).

Apesar de ser encontrada em todo o Brasil, essa zoonose ocorre com maior frequência em áreas que não dispõem de sistemas de criação de gado adequados, de condições satisfatórias de abate e que carecem de inspeção sanitária dos animais abatidos (Almeida et al., 2002; Silva e Silva, 2007).

A inspeção higiênico-sanitária e tecnológica (HST) de carnes em abatedouros, realizada pelos serviços de inspeção sanitária oficial, nos níveis federal, estadual ou municipal, é uma forma eficiente e eficaz de controle do complexo teníase-cisticercose. Nos estabelecimentos de abate, o diagnóstico de cisticercose é feito durante a inspeção post mortem dos animais pela avaliação de áreas específicas no animal, como coração, músculos da mastigação, língua, diafragma e seus pilares, bem como músculos de fácil acesso de inspeção obrigatória. No entanto, a sensibilidade desse método é baixa, especialmente em infecções leves (Brasil, 1980; Minozzo et al., 2004). Dessa maneira, testes imunológicos, como o Enzyme Linked Immunosorbent Assay (ELISA) e o Immunoblot, que utilizam extratos antigênicos de larvas de $T$. saginata, $T$. solium e T. crassiceps, têm sido utilizados experimentalmente como métodos de diagnóstico ante mortem da cisticercose bovina, o que pode contribuir para aumentar a precisão dos dados oficiais em estabelecimentos inspecionados e servir de instrumento para a coleta de dados em estudos epidemiológicos e no monitoramento de parasitoses em animais de abate (Girotto et al., 2009; Santos, 2010).

Apesar dos impactos sobre a saúde humana e a animal e dos prejuízos econômicos gerados, a situação epidemiológica do complexo teníasecisticercose no Brasil é pouco conhecida, devido ao fato de a teníase humana não exigir notificação compulsória e também de haver limitações na fiscalização de carnes no país, notadamente nos pequenos municípios, onde predomina o abate não inspecionado (Almeida $e t$ al., 2002; Agapejev, 2003). A maior parte dos dados disponíveis sobre a prevalência da cisticercose em bovinos foi obtida dos registros dos serviços de inspeção oficiais em abatedouros e não associa a ocorrência e a manutenção do complexo teníase-cisticercose bovina com os possíveis fatores de risco, relacionados às condições socioeconômicas e culturais da população, especialmente em municípios do interior e em áreas mais pobres. Dessa maneira, este trabalho vai além de uma simples verificação da prevalência da cisticercose bovina.

O objetivo deste trabalho foi realizar a caracterização da situação do complexo teníasecisticercose em Minas Gerais, Brasil, pela estimativa da prevalência da cisticercose bovina e da teníase humana em função dos fatores de risco relacionados às condições sanitárias e socioeconômicas da população rural do município selecionado.

\section{MATERIAL E MÉTODOS}

Foi selecionado o município de São João Evangelista, situado na região centro-nordeste de Minas Gerais, Brasil, que possui 747 estabelecimentos agropecuários, população estimada de 16.254 habitantes e uma área de $479 \mathrm{~km}^{2}$ (IBGE, 2006).

Para o cálculo amostral, foram utilizados como parâmetros: prevalência estimada de $2 \%$ para a cisticercose, precisão de $1,5 \%$ e nível de significância de 5\% (Epi Info, versão 3.5.1; CDC, 2008). A amostragem foi calculada considerando-se o número total de 24.070 bovinos na região (IBGE, 2006). Dessa maneira, foram coletadas amostras de sangue de 339 bovinos, com idade variando entre sete meses e 10 anos, provenientes de 15 propriedades sorteadas aleatoriamente, abrangendo todas as macrorregiões do município (norte, sul, centro, 
leste e oeste) e um total de 12 comunidades rurais.

Em cada propriedade foi aplicado um questionário socioeconômico, com a finalidade de se obterem dados sobre possíveis fatores de risco para a teníase humana e a cisticercose bovina. No questionário socioeconômico, foram abordadas questões relacionadas à ocupação das pessoas residentes, à renda familiar, à fonte de água para pessoas e animais, à disposição do esgoto sanitário, ao conhecimento sobre a doença, à forma de consumo da carne e à presença de fonte de irrigação da horta nas propriedades. Foi realizada também a coleta de fezes de todos os habitantes das propriedades, com idade variando entre quatro e 74 anos de idade, para realização do exame coproparasitológico para pesquisa de ovos de Taenia spp. por sedimentação espontânea, pelo método de Hoffman, Pons e Janer - HPJ (UFSC, 2002).

Para o diagnóstico sorológico da cisticercose bovina, as amostras de sangue dos animais, coletadas por punção da veia jugular, foram mantidas em temperatura ambiente para a separação do soro e, em seguida, armazenadas a $20^{\circ} \mathrm{C}$. O método ELISA indireto foi utilizado como teste de triagem, e as amostras positivas foram submetidas ao Immunoblot para confirmação.

Os testes sorológicos, ELISA e Immunoblot, foram realizados utilizando-se o antígeno de líquido vesicular de Taenia crassiceps (LVcra), que foi preparado com a centrifugação dos parasitas íntegros a $35.000 x g$ por 30 minutos a $4{ }^{\circ} \mathrm{C}$. Após a centrifugação, o sobrenadante foi coletado e a ele foi adicionado inibidor de protease (fluoreto de fenilmetilsulfonil - PMSF, Sigma Aldrich Co., St. Louis, MO, USA) na concentração de $2,5 \mathrm{mM}$ de extrato antigênico. $\mathrm{O}$ antígeno LVcra preparado foi mantido a $-20^{\circ} \mathrm{C}$ (Girotto et al., 2009).

Para realização do ELISA indireto, as placas de poliestireno foram sensibilizadas com os antígenos diluídos $(10 \mu \mathrm{g} / \mathrm{mL})$ em solução tamponada carbonato-bicarbonato 0,5M, pH 9,6. Foram adicionados $100 \mu \mathrm{L}$ da solução em cada poço e a placa foi incubada durante uma hora a $37^{\circ} \mathrm{C}$. Após três lavagens, de cinco minutos cada, com solução salina contendo $0,05 \%$ (v/v) de Tween 20, foi realizado o bloqueio dos sítios reativos com $200 \mu \mathrm{L}$ de solução de leite desnatado a $5 \%$ em $\mathrm{PBS}, \mathrm{pH} 7,4$, por poço, durante uma hora a $37^{\circ} \mathrm{C}$. Após essa etapa, foram realizadas novas lavagens, de acordo com os procedimentos descritos anteriormente, e foram acrescentados $100 \mu \mathrm{L}$ de amostra (em solução de diluição) por poço. As amostras foram analisadas em triplicata, e a placa foi incubada por 30 minutos a $37^{\circ} \mathrm{C}$. Após três lavagens, foi adicionado o conjugado anti-IgG de bovino A5295 (Sigma Aldrich Co., St. Louis, MO, USA) em diluição 1:5000, e repetiram-se os procedimentos de incubação e lavagem da última etapa. A reação foi revelada com $100 \mu \mathrm{L} /$ poço de solução de OPD $(0,1 \%)$ e $\mathrm{H}_{2} \mathrm{O}_{2} \quad 0,0003 \%$ em tampão citrato-fosfato $0,2 \mathrm{M}$ e pH 5,0, durante um período de incubação de cinco minutos a $37^{\circ} \mathrm{C}$. As leituras das amostras foram realizadas em espectrofotômetro a $492 \mathrm{~nm}$, e seus resultados expressos em densidade óptica.

Para as análises pela técnica do Immunoblot, foi realizada a separação dos peptídeos do antígeno vesicular de $T$. crassiceps por eletroforese em gel de gradiente $(4 \%$ a $12,5 \%)$ de poliacrilamida (SDS-PAGE) em sistema descontínuo, segundo Laemmli (1970), citado por Girotto et al. (2009). Foi utilizado marcador de peso molecular de 6,500 a 200,000Da (Sigma S8445, Sigma Aldrich Co., St. Louis, MO, USA). Os peptídeos separados por SDS-PAGE foram transferidos do gel para membranas de nitrocelulose de $0,2 \mu$ (Millipore, USA), utilizando-se solução tamponada de transferência contendo metanol, $\mathrm{pH} 8,3$, segundo a metodologia descrita por Towbin et al. (1979). A transferência foi realizada em um sistema semisseco, no equipamento Sem-Dry Transfer Cell, com corrente de $130 \mathrm{~mA}$ e voltagem constante de $15 \mathrm{~V}$ (Bio-Rad Laboratories, Hercules, CA, USA), sendo usado o antígeno LVcra na concentração de $6 \mu \mathrm{g} / \mathrm{mm}$ (Pinto et al., 2000). Após a transferência, as membranas de nitrocelulose foram coradas em solução aquosa contendo Ponceau-S a $0,5 \%$, e as tiras obtidas das membranas foram acondicionadas em bandejas fenestradas. Após a lavagem com água destilada, foi acrescentado $1,0 \mathrm{~mL}$ de solução bloqueadora $(\mathrm{pH} \mathrm{7,4)}$ às tiras, que permaneceram em mesa oscilante por uma hora. Em seguida, foi realizada uma lavagem rápida em solução salina. As amostras de soro na concentração 1:100, em solução de diluição, foram adicionadas às tiras (1,0mL/canaleta) com posterior incubação por 
14-18 horas, a $4^{\circ} \mathrm{C}$. Após a lavagem, foi adicionado a cada tira $1,0 \mathrm{~mL}$ de solução do conjugado anti-IgG de bovino A-5295 (Sigma Aldrich Co., St. Louis, MO, USA), em diluição 1:500, e as bandejas permaneceram sobre uma mesa oscilante por uma hora. Após retirar o conjugado, os peptídeos reativos foram evidenciados com o acréscimo de $1,0 \mathrm{~mL}$ de solução cromógena por cerca de 10 minutos. Em seguida, a reação foi bloqueada com a lavagem das tiras em água destilada e posterior secagem sobre papel-filtro para avaliação.

Em todas as análises, foram utilizados controles positivos e negativos, na diluição 1:50. Os soros sanguíneos usados como controle positivo foram obtidos de animais inoculados experimentalmente, e, como controle negativo, foi utilizado soro de animais criados separadamente e comprovadamente livres de infecção por ovos de Taenia spp.

Os resultados das análises laboratoriais e os dados extraídos dos questionários foram armazenados em bancos de dados do Programa Epi Info, versão 3.5.1. (CDC, 2008). As variáveis quantitativas foram avaliadas pela análise de variância e pelo teste $t$ de Student, e as qualitativas foram analisadas por tabela de contingência $2 \times 2$, utilizando-se o teste de quiquadrado e o teste de Fisher, assim como pela intensidade de associação entre as variáveis pelo cálculo da razão de chances (Odds ratio) e respectivos intervalos de confiança a $5 \%$ de significância.

\section{RESULTADOS E DISCUSSÃO}

Os resultados dos testes de triagem, realizados pelo ELISA indireto, demonstraram que das 15 propriedades avaliadas, $12(80 \%)$ foram consideradas suspeitas para a cisticercose bovina, e dos 339 animais avaliados foram encontrados $36(10,62 \%)$ suspeitos. Pela metodologia do Immunoblot, nove propriedades foram confirmadas como positivas para a cisticercose bovina, correspondendo a $60 \%$ do total de propriedades avaliadas. Dos animais avaliados, 14 foram confirmados como positivos, representando uma prevalência de $4,1 \%$ em relação aos 339 animais amostrados, com idade variando entre sete meses e 10 anos. Essa prevalência para cisticercose bovina, quando somada ao desvio-padrão calculado $(2,0)$, iguala- se estatisticamente ao índice de 5,0\%, considerado endêmico segundo a Organização Mundial da Saúde (OMS), constituindo um importante problema de saúde pública (OMS, 2009). O exame coproparasitológico, realizado em um total de 34 indivíduos residentes nas propriedades rurais amostradas, apresentou apenas uma amostra positiva, o que correspondeu a uma frequência de 2,94\% de teníase humana. Esse valor foi superior ao índice endêmico, que é de $1,0 \%$, demonstrando a necessidade de intervenção dos órgãos responsáveis para estabelecer medidas de controle no município estudado. Porém, para outros helmintos, foram encontradas 27 amostras positivas, o que indica uma prevalência de $79,41 \%$, sendo 15 amostras $(44,12 \%)$ positivas para Ascaris spp., cinco $(14,70 \%)$ positivas para Ancilostomídeos, uma $(2,94 \%)$ positiva para Enterobius spp., quatro $(11,76 \%)$ positivas para Strongyloides spp. e duas $(5,88 \%)$ positivas para Trichuris spp. A baixa prevalência de teníase humana em relação a outras parasitoses intestinais também foi observada por outros autores e pode ser explicada pela baixa sensibilidade do exame, pelas mudanças no sistema de criação de gado, pelas melhorias nos sistemas de saneamento básico para disposição de dejetos humanos e pelas ações de educação sanitária (Cruz-Licea et al., 2003; Ramos Jr. et al., 2004).

Segundo os dados obtidos pelas análises dos questionários aplicados, das propriedades amostradas, 14 (93\%) foram representadas por seus proprietários e somente uma foi representada por um caseiro. Com relação à ocupação, 73,3\% dos indivíduos eram produtores rurais ou pecuaristas e $26,7 \%$ possuíam outras ocupações, que variavam entre comerciante, técnico agropecuário, professor e funcionário público. A renda familiar mensal foi de até dois salários mínimos (valor de referência: $\mathrm{R} \$$ $510,00)$ em $50 \%$ das famílias, que eram constituídas, em média, por quatro pessoas $(4 \pm 1,57)$, alcançando o número máximo de nove pessoas.

Foi observado que, em $12(80 \%)$ propriedades estudadas, as pessoas consumiam água de mina ou nascente, enquanto duas $(13,3 \%)$ fazendas possuíam poço artesiano e apenas uma recebia água tratada da Companhia de Saneamento de Minas Gerais (Copasa). Apesar de 13 (86,7\%) 
propriedades possuírem água canalizada, somente uma realizava sua filtração antes do consumo. Duas propriedades $(13,3 \%)$ não possuíam água canalizada e utilizavam latão como reservatório. Quanto à fonte de água para os animais, em sete $(46,7 \%)$ propriedades a água era proveniente de rio ou ribeirão, em cinco $(33,3 \%)$, era oriunda de mina ou nascente e em três $(20 \%)$, de poço artesiano. Dessa maneira, nenhum animal avaliado recebia água tratada. A disposição do esgoto sanitário era realizada em fossas em oito $(53,3 \%)$ propriedades; ele era eliminado em rio ou ribeirão em cinco fazendas $(33,3 \%)$ e destinado a outros locais em duas propriedades (13,3\%). Rezende et al. (2006) detectaram cisticercose em bovinos criados em locais que não possuíam saneamento básico, com lançamento de esgoto a céu aberto, e concluíram que essa condição pode ter favorecido a infecção dos animais. A falta de fossas ou de tratamento do esgoto favorece a contaminação de mananciais por ovos de $T$. saginata, que podem ser dispersos por longas distâncias e permanecerem viáveis no meio hídrico. Assim, os bovinos criados em sistemas extensivos, que bebem água proveniente de nascentes, rios e córregos, estão expostos a infecções transmitidas pela água contaminada, quando não há tratamento adequado antes do fornecimento aos animais (Ungar et al., 2008; Allepuz et al., 2009).

Todos os responsáveis pelas fazendas que foram entrevistados relataram saber o que era a doença, conhecida popularmente como "canjiquinha" ou "pipoca". Destes, $11(73,3 \%)$ já observaram a presença de cistos em carne suína e dois $(13,3 \%)$ observaram cistos parasitários em carne exposta à venda no mercado da região. Todos os entrevistados possuíam o hábito de consumir carne bovina e em cinco propriedades $(33,3 \%)$ os entrevistados relataram ter preferência pela carne malpassada. Como não existem matadouros de bovinos inspecionados no município, os animais são abatidos sem inspeção sanitária oficial, e, dessa forma, a carne consumida pela população representa um risco em relação à disseminação de doenças como a teníase. Rezende et al. (2006) avaliaram a ocorrência de cisticercose em bovinos abatidos clandestinamente em Silva Jardim, Rio de Janeiro, e observaram que as carcaças foram comercializadas normalmente e destinadas ao consumo humano, apesar de 13
$(21,7 \%)$ animais abatidos, de um total de 60 , apresentarem cisticercose

Em relação à vermifugação humana, em apenas seis propriedades $(40 \%)$ as pessoas residentes possuíam o hábito de realizá-la periodicamente.

A maior parte das propriedades $(73,3 \%)$ praticava cultivo de horta, e todas consumiam o que produziam. Os animais não tinham acesso às hortas, e 81,8\% delas eram cercadas. Quanto à irrigação, $81,8 \%$ era irrigada com água de mina ou nascente e $18,2 \%$ com água de poço artesiano ou cisterna. $\mathrm{O}$ hábito de consumir verduras foi relatado em 93,3\% das propriedades, e em todas havia a preferência por saladas cruas, que se torna um risco quando contaminadas com ovos do parasita.

Entre os fatores de risco inerentes à transmissão e à manutenção do complexo teníase-cisticercose bovina que foram avaliados, apenas a preferência pelo consumo de carne malpassada pela população amostrada apresentou relação significativa $(\mathrm{P}<0,05) \quad$ com a prevalência encontrada para a cisticercose bovina, com o valor de $\mathrm{P}=0,042$ no teste de Fisher. A ingestão de carne crua ou malcozida contendo cisticercos viáveis é a principal fonte de transmissão da teníase ao hospedeiro definitivo, o homem, mantendo o ciclo biológico da doença no ambiente (Silva, 2005; Ungar et al., 2008). Wandra et al. (2006) estudaram a prevalência de teníase por T. saginata em Bali, na Indonésia, e observaram que todos os indivíduos infectados possuíam o hábito de consumir carne crua.

Uma propriedade apresentou-se positiva para cisticercose bovina e teníase humana, havendo a possibilidade de fechamento do ciclo da doença. Nesse caso, os fatores de risco para a manutenção do complexo teníase-cisticercose foram os seguintes: baixa renda familiar, fornecimento de água de rio ou ribeirão para os animais e presença de horta para consumo próprio irrigada com água de mina ou nascente. Além disso, as pessoas residentes não possuíam o hábito de realizar tratamento periódico com vermífugo.

Os resultados encontrados no presente estudo reforçaram a necessidade de implantação do controle higiênico-sanitário e tecnológico (HST) na obtenção da carne bovina em São João Evangelista e da eliminação do abate não 
inspecionado, pois o consumo de carne malpassada e não inspecionada foi considerado o principal fator de risco para a ocorrência e a manutenção do complexo teníase-cisticercose bovina. Além dessa medida, o controle do comércio varejista de carnes e derivados pela vigilância sanitária municipal também é importante para impedir a comercialização de carnes não inspecionadas, infectadas com o $C$. bovis, que representam um risco para a saúde do consumidor.

\section{CONCLUSÃO}

A cisticercose bovina, determinada pelo ELISA e pelo Immunoblot, está presente e se distribui de forma endêmica em Minas Gerais, especificamente no município de São João Evangelista. As condições sanitárias, socioeconômicas e culturais da população rural desse município são favoráveis à ocorrência e à manutenção do complexo teníase-cisticercose bovina, e o consumo de carne bovina, sem inspeção sanitária e malpassada, continua sendo o fator mais significativo na epidemiologia desse complexo.

\section{REFERÊNCIAS}

AGAPEJEV, S. Aspectos clínico-epidemiológicos da neurocisticercose no Brasil: análise crítica. Arq. Neuropsiq., v.61, p.822-828, 2003.

ALLEPUZ, A.; NAPP, S.; PICADO, A. et al. Descriptive and spatial epidemiology of bovine cysticercosis in NorthEastern Spain (Catalonia). Vet. Parasitol., v.159, p.43-48, 2009.

ALMEIDA, L.P.; MOREIRA, M.D.; REIS, D.O. et al. Cisticercose bovina: um estudo comparativo entre animais abatidos em frigoríficos com serviço de Inspeção Federal e com Inspeção Municipal. Hig. Aliment., v.16, p.51-55, 2002.

BRASIL. Ministério da Agricultura. Regulamento da Inspeção Industrial e Sanitária de Produtos de Origem Animal (RIISPOA). (Aprovado pelo Decreto $\mathrm{n}^{\circ}$ 30.691, de 29/03/1952, alterado pelo Decreto ${ }^{\circ} 1.255$, de 25/06/1962). Diário Oficial da União. Brasília, 1980, 154p.

CENSO Agropecuário/IBGE 2006, São João Evangelista-MG. IBGE, Disponível em: <www.ibge.gov.br> Acesso em: Mar. 2010.
CRUZ-LICEA, V.; PLANCARTE-CRESPO, A.; MORAN, I. et al. Teniosis y cysticercosis en comerciantes de alimentos en mercados de uma área de la ciudad de Mexico. Parasitol. Latinoam., v.58, p.41-48, 2003.

Epi Info 3.5.1, versão 18 de agosto de 2008. CDC Centers for Disease Control and Prevention., 2008. Disponível em: <wwwn.cdc.gov/epiinfo>. Acessado em: 14 jan. 2015.

GIROTTO, A.; PINTO, P.S.A.; DIAS, J.C.O. et al. Detecção de peptídeos importantes para o diagnóstico da cisticercose bovina no Imunoblot. Cienc. Rural, v.39, p.1136-1140, 2009

MÉTODOS de exames coprológicos. Laboratório de Protozoologia. Santa Catarina: Universidade Federal de Santa Catarina - Departamento de Microbiologia e Parasitologia , 2002.

MINOZZO, J.C.; THOMAZ-SOCCOL, V.; OLORTEGUI, C.C. et al. Teste imunoenzimático (enzyme-linked immunosorbent assay) para diagnóstico da cisticercose bovina e estudo da cinética da produção de anticorpos contra Cysticercus bovis. Ciênc. Rural., v.34, p.857-864, 2004.

PFUETZENREITER, M. R.; ÁVILA-PIRES, F. D. Epidemiologia da teníasecisticercose por Taenia solium e Taenia saginata. Ciênc. Rural, v.30. p.541548, 2000.

PINTO, P.S.A; VAZ, A.J.; GERMANO, P.M.L. et al. Perfomance of the ELISA test for swine cysticercosis using antigens of Taenia solium and Taenia crassiceps cysticerci. Vet. Parasitol., v.88, p.127-130, 2000.

RAMOS JR, A.N.; MACEDO, H.W.; RODRIGUES, M.C. et al. Estudo soroepidemiológico da cisticercose humana em um município do Estado do Piauí, Região Nordeste do Brasil. Cad. Saúde Pública, v.20, p.15451555, 2004.

REPORT of the WHO Expert Consultation on Foodborne Trematode Infections and Taeniasis/Cysticercosis. Vientiane, Lao People's Democratic Republic: World Health Organization, 2009. Disponível em: <http://www.who.int/ neglected_diseases/preventive_chemotherapy/WHO_ HTM_NTD_PCT_2011.3.pdf.> Acesso em: 24 maio. 2011.

REZENDE, R.B.C.; FERNADEZ, A.T.; COSTA, F. et al. Ocorrência de cisticercose em bovinos abatidos clandestinamente no município de Silva Jardim, RJ. Revr. Hig. Alim. v. 21, p.103-109, 2006.

SANTOS, T.O. Levantamento epidemiológico do complexo teníase-cisticercose na zona rural do município de Viçosa - MG. 2010. 67f., Dissertação (Mestrado em Medicina Veterinária) - Escola de Veterinária, Universidade Federal de Viçosa, Viçosa, MG. 
SILVA, A.V.M. Teníase e cisticercose. In: NEVES. D.P. Parasitologia humana. 11.ed. Atheneu: São Paulo, 2005. Cap. 25, p. 227-236.

SILVA, A.A.P.; SILVA, M.V. Teníase na população do bairro Nossa Senhora Aparecida município de Correia Pinto-SC, em 2003 e 2004. Rev. Bras. Anal. Clin. v.39, p.143-145, 2007.

TOWBIN, H.; STAEHELIN, T.; GORDON, J. Eletrophoretic transfer of proteins from polyacrylamide gels to nitrocellulose sheets: procedure and some applications. Proc. Natl. Acad. Sci. USA, v.76, p.4350-4352, 1979.
UNGAR, M.L.; GERMANO, M.I.S.; GERMANO, P.M.L. Cisticercose bovina. In: GERMANO, P.M.L.; GERMANO, M.I.S. Higiene e vigilância sanitária de slimentos. 3.ed. São Paulo: Editora Manole, 2008. p.449-461.

WANDRA, T.; SUTISNAC, P.; DHARMAWAND, N.S. et al. High prevalence of Taenia saginata taeniasis and status of Taenia solium cysticercosis in Bali, Indonesia, 2002-2004. Trans. R. Soc. Trop. Med. Hyg. v.100, p.346-353, 2006. 